\title{
Network Monitoring System Data Radar Penerbangan berbasis PRTG dan ADSB
}

\author{
Nor Alip ${ }^{1}$, Iskandar Fitri ${ }^{2}$, Novi Dian Nathasia ${ }^{3}$. \\ 1alipnor@gmail.com, 2tekte12001@yahoo.com, 3novidian@civitas.unas.ac.id
}

\begin{abstract}
Program Studi Teknik Informatika, Fakultas Teknologi Komunikasi dan Informatika, Universitas Nasional
\end{abstract}
\begin{abstract}
The development of network infrastructures in the current flight navigation is very rapidly. It requires the presence of a network device management to manage the availability of Automatic Dependant a Surveillance Broadcast (ADSB) and radar (radio detection and ranging) data. To manage the network device, it needs a system like Network Monitoring System (NMS). NMS is a system for managing Internet Protocol (IP)-based network devices. To run the NMS, it takes an order or the underlying protocol, i.e. Simple Network Management Protocol (SNMP). SNMP protocol allows administrators to manage and organise the performance of network devices remotely. This paper will discuss "the implementation of Network Monitoring System for ADSB and flight radar data based-on Paessler Router Traffic Grapher (PRTG). The NMS implementation uses a PRTG application. Use PRTG to monitor the bandwidth usage against the radar and data as well as the $A D S B$ monitor the condition of all devices. SNMP-based measurements only based on port. The software also allows to rapidly prepare and run a monitoring process to a specific network. With this then the PRTG can easily find out the number of radar data and the ADSB flowing through the router device as well as knowing the condition of all the routers that are connected with PRTG and expedite the handling of the case of interference with such notification.
\end{abstract}

Abstrak - Perkembangan infrastruktur jaringan dalam navigasi penerbangan saat ini sangat pesat, sehingga diperlukan adanya suatu manajemen perangkat jaringan untuk mengelola ketersediaan ADSB dan data radar. Untuk mengelola perangkat jaringan tersebut, dibutuhkan suatu sistem seperti NMS. NMS merupakan suatu sistem untuk mengelola perangkat-perangkat jaringan berbasis IP. Untuk menjalankan NMS, dibutuhkan suatu aturan atau protokol yang mendasari sistem tersebut, protokol tersebut adalah SNMP. Protokol SNMP memungkinkan administrator untuk mengelola dan mengatur kinerja perangkat jaringan secara jarak jauh. Pada artikel ini akan dipaparkan "Implementasi Network Monitoring System untuk ADSB dan data radar Penerbangan berbasis PRTG'. Implementasi NMS ini menggunakan sebuah aplikasi yaitu PRTG. PRTG digunakan untuk memantau penggunaan bandwidth terhadap ADSB dan data radar serta memantau kondisi semua perangkat. Pengukuran berbasis SNMP hanya berbasis pada port. Software ini juga memungkinkan untuk secara cepat mempersiapkan dan menjalankan sebuah proses pemantauan untuk sebuah jaringan tertentu. Dengan PRTG ini maka dengan mudah dapat mengetahui jumlah data radar dan ADSB yang mengalir melalui perangkat router serta mengetahui kondisi semua perangkat router yang terhubung dengan PRTG serta mempercepat penanganan jika terjadi gangguan dengan adanya notifikasi.

KataKunci-network monitoring system, radar, ADSB, PRTG, SNMP.

\section{PENDAHULUAN}

Akses terhadap data radar yang handal sangat dibutuhkan untuk mendapatkan dan memudahkan proses navigasi penerbangan. Permintaan akan kebutuhan ADSB dan data radar yang real time serta penanganan gangguan yang cepat sangat dibutuhkan untuk menentukan posisi suatu pesawat terbang. Oleh karena itu dibutuhkan sebuah perangkat yang memonitor dan memberikan notifikasi jika terjadi gangguan. Implementasi monitoring data dalam jaringan untuk penerbangan sangat dibutuhkan agar kualitas layanan meningkat dan penanganan gangguan lebih cepat[1].

Sebelum adanya alat yang mampu memonitor ketika terjadi gangguan, harus menunggu komplain dari pemakai terlebih dulu, yang ditindak-lanjuti dengan melakukan pemeriksaan terhadap data radar maupun ADSB. Untuk penanganannya terlebih dahulu melakukan tes koneksi (ping) dan masuk ke IP router tersebut dan apabila reply dan data radar ataupun ADSB counter maka dapat dipastikan link normal[2].

Untuk mengatasi masalah diatas maka diperlukan sebuah monitoring system yang mampu mendeteksi setiap masalah ataupun gangguan pada sistem baik hardware, software maupun aplikasi yang ada di perangkat tersebut serta mempunyai log disetiap terjadinya ganguan secara detail. Sehingga mempermudah administrator untuk dapat menganalisa penyebab terjadinya gangguan secara cepat[3].

Salah satu tools yang sangat bagus untuk mengimplementasikan scenario diatas adalah PRTG. PRTG tersedia dalam empat pilihat lisensi, yaitu Freeware Edition, 
Special Edition, Trial Edition, dan Commercial Editions.PRTG dapat berjalan pada Windows dalam jaringan. PRTG mengumpulkan berbagai statistik dari hardware, software, dan perangkat lain yang ditentukan. PRTG juga menyimpan data statistik yang telah dikumpulkan. Sehingga penggunanya dapat melihat riwayat kerja perangkat yang dimonitor serta dapat merespon perubahan yang terjadi[4].

PRTG mampu mendukung SNMP, packet sniffing, atau Cisco NetFlow yang memungkinkan untuk pengukuran trafik berdasarkan alamat IP dan atau protocol. Pada jurnal sebelumnya pengkonfigurasian dan perancangan NMS dengan menerapkan protocol SNMP dapat memonitor jaringan skala kecil maupun skala besar seperti Data Center dengan baik[5].

Pada penelitian lainya, PRTG digunakan untuk memonitor trafik penggunaan bandwidth. Sistem monitoring aplikasi PRTG dapat dijalankan sebagai fungsi monitoring terhadap host server maupun router, sehingga setiap host dapat dipantau setiap saat.

\section{KAJIAN PUSTAKA}

Dalam perancangan yang diimplementasikan adalah suatu Network Monitoring System yang dapat digunakan untuk memantau trafik penggunaan ADSB dan data radar serta memantau kondisi perangkat agar bekerja secara optimal, nantinya akan diintegrasikan menjadi suatu NMS yang dapat berfungsi sebagaimana yang diharapkan.

Flowchart proses Perancangan Monitoring ADSB dan data radar :

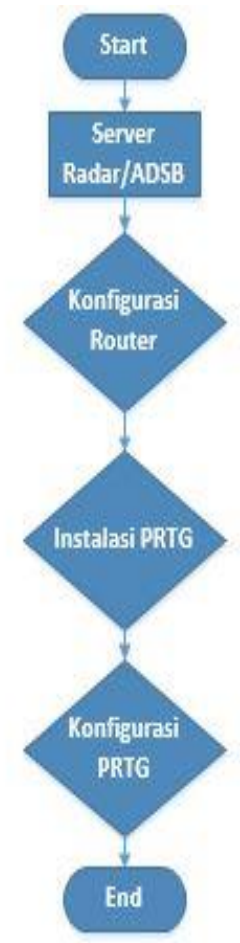

Gambar 1. Flowchart Implementasi PRTG.
Flowchart diatas sebagai gambaran untuk memberi penjelasan proses berjalannya implementasi PRTG untuk memonitor trafik penggunaan ADSB dan data radar. Dimulai dengan konfigurasi router agar terkoneksi ke server ADSB dan radar, kemudian instalasi PTRG dan mengkonfigurasikan NMS PRTG agar terhubung ke router sehingga dapat memantau trafik melaui SNMP pada router.

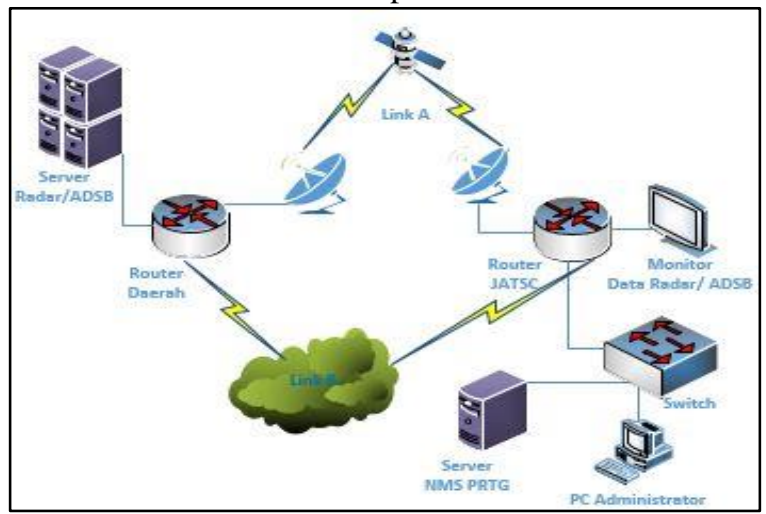

Gambar 2. Skema Perancangan Topologi Jaringan

Topologi diatas berupa rancangan untuk menghubungkan data radar dan ADSB di suatu daerah ke router yang ada di Jakarta menggunakan jaringan private dengan tunnel link.Server pemantau jaringan diletakkan pada jaringan private yang ada di pusat. Untuk menghubungkan PC pemakai ke NMS PRTG, pemakai memerlukan jaringan intranet yang diberikan layanannya, yaitu oleh kantor pusat Gd. Tower ATC bandara Soekarno-Hatta. Dengan begitu maka semua jaringan intranet dapat termonitoring dengan baik melalui PRTG.

Pada implementasi ini penulis memerlukan hardware seperti PC / Laptop, Cisco router 3900, dan Switch. Sedangkan sistem operasi yang dibutuhkan adalah Cisco IOS 15.0, Windows Server 2012 R2.

Beberapa tools dan utility yang digunakan untuk mengoperasikan PRTG.

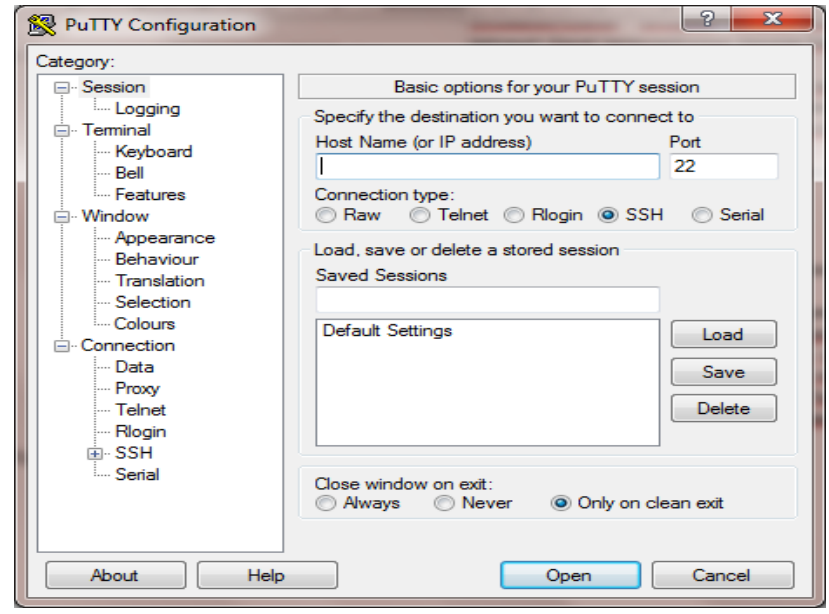

Gambar 3. Tampilan utama PuTTY. 
PuTTYadalah sebuah program open source yang dapat digunakan untuk melakukan protokol jaringan SSH, Telnet dan Rlogin.Protokol ini dapat digunakan untuk menjalankan sesi remote pada sebuah komputer melalui sebuah jaringan, baik itu LAN, maupun internet.Program ini banyak digunakan untuk menyambungkan, mensimulasi, atau mencoba berbagai hal yang terkait dengan jaringan.Program ini juga dapat gunakan sebagai tunnel di suatu jaringan.

Mozilla FirefoxBrowser digunakan untuk menampilkan dan menkonfigurasi PRTG secara GUI (Graphical User Interface).

\section{METODOLOGI PENELITIAN}

Dalam penelitian ini terdiri dari tiga tahapan. Pertama konfigurasi SNMP pada Cisco router. Kedua Instalasi dan konfigurasi PRTG pada Windows Server 2012. Ketiga konfigurasi email notifikasi pada PRTG. Ketiga tahapan tersebut lebih detailnya dibahas pada sub bab.

\section{A. Konfigurasi SNMP pada CISCO router}

Hal pertama yang perlu dilakukan pada perancangan perangkat keras ini adalah menghubungkan router dan switch, selajutnya melakukan konfigurasi SNMP pada setiap router agar nantinya dapat dilakukan monitoring pada perangkat tersebut.

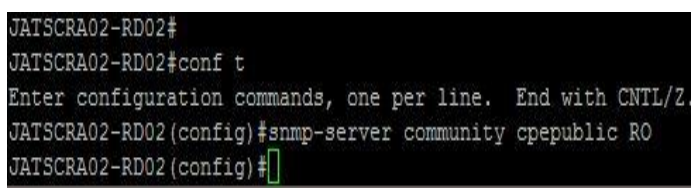

Gambar 4. Konfigurasi SNMP Community pada router.

Gambar diatas adalah konfigurasi SNMP yang nantinya harus dimasukan dalam setiap router supaya semua router bis a terhubung dengan PRTG.

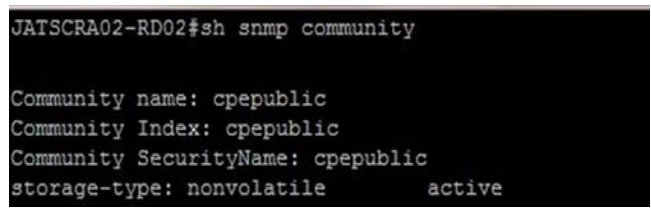

Gambar 5. Hasil konfigurasi SNMP Comunity pada router.

Gambar diatas adalah hasil dari konfigurasi SMNP pada router dimana community name dan community index serta community securityname adalah cpepublic.

\section{B. Instalasi Dan Konfigurasi PRTG Pada Windows Server 2012 R2}

Untuk install PRTG buka file installer PRTG $\rightarrow$ double click $\rightarrow$ pilih bahasa $\rightarrow$ click next $\rightarrow$ pada tampilan License Agreement pilih I accept the agreement $\rightarrow$ click next $\rightarrow$ masukan alamat email $\rightarrow$ click next $\rightarrow$ masukan key yang diminta $\rightarrow$ click next $\rightarrow$ finish.

Selanjutnya buka PRTG Network Monitor di desktop kemudian akan terbuka akan langsung membuka web browser PRTG atau buka http://127.0.0.1/index.htm, login PRTG dengan username prtgadmin dan password dengan prtgadmin.
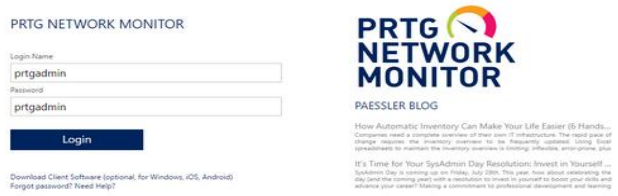

Gambar 6. Tampilan login PRTG

Gambar diatas merupakan tampilan awal di mozilla firefox ketika membuka PRTG pertama kali, dan pengguna diminta untuk memasukan login name dan password untuk dapat mengakses PRTG.

Selanjutnya adalah menambahkan deviceyag akan dimonitor menggunakan PRTG, pertama pilih Devices $\rightarrow$ click Add Device kemudian pilih group yang diinginkan lalu click continue, pada device name masukan mana yang diinginkan kemudian isikan ip address sesuai ip pada perangkat. Kemudianpada tags pilih sensor yang akan digunakan seperti bandwidth sensor, SNMP CISCO system health sensor, SNMP traffic sensor, danSNMP uptime sensor. Kemudian pada credentials for SNMP devices pilih $v 2 c$, untuk community string masukanSNMP community yang dikonfigurasi pada router yaitu cpepublic. Untuk port pilih161 dan SNMP timeout pilih 5.Pada Device Type untuk sensor management pilih Automatic device identification dan discovery schedule pilih once.Setelah itupilih continue.

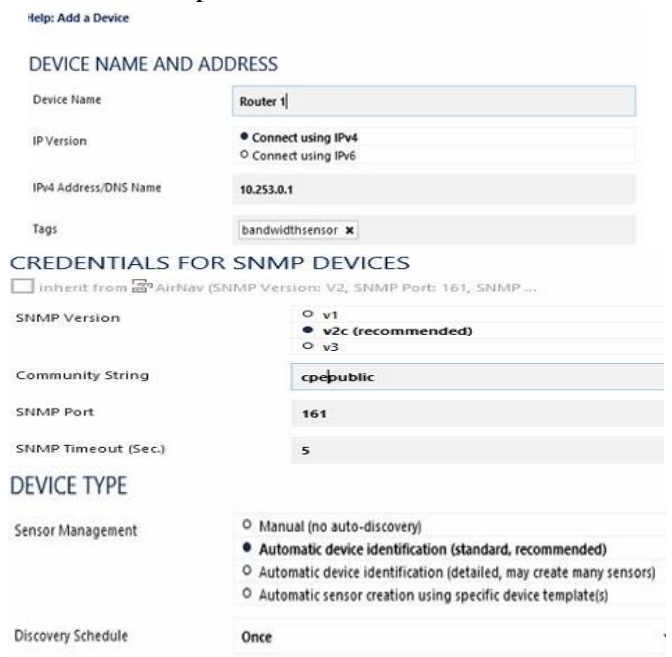

Gambar 7. Konfigurasi PRTG untuk menambahkan device

Gambar 7 menampilkan konfigurasi untuk menambahkan device ke dalam PRTG agar setiap perangkat dapat dimonitor berdasarkan sensor yang telah dipilih, konfigurasi ini harus ditambahkan disetiap router. 


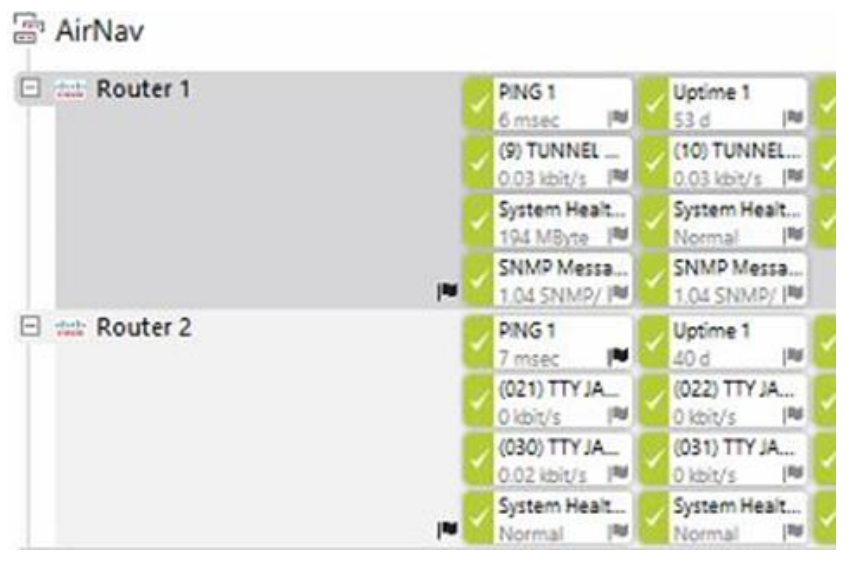

Gambar 8 menunjukan bahwa device sudah selesai dikonfigurasi dan sensor yang pilih sudah berhasil terpasang pada masing-masing perangkat.

\section{Konfigurasi Email Notifikasi Pada PRTG}

Untuk mengaktifkan email notifikasi pada PRTG, buka PRTG $\rightarrow$ pilih setup $\rightarrow$ account settings $\rightarrow$ notifications $\rightarrow$ click add notification kemudian isi notification name dan notification summarization $\rightarrow$ pilih send email lalu pada send to email address masukan alamat email yang akan digunakan untuk mengirim notifikasi kemudian click save.

Kemudian untuk mengaktifkan notifikasi tersebut pilih menu libraries $\rightarrow$ select library kemudian pilih sensor yang ingin diaktifkan notifikasinya, selanjutnya click notifications $\rightarrow$ click add state trigger dan masukan parameternya kemudian click save.

Gambar 9 menunjukan bahwa notifikasi email telah berhasi ditambahkan, dan nantinya akan memberikan notifikasi kedalam email administrator jika terjadi gangguan atau kendala pada setiap perangkat.

\begin{tabular}{|c|c|c|c|c|}
\hline \multicolumn{5}{|c|}{ Account Settings } \\
\hline (\$i) My Account & $\sum$ Notifications & $\otimes$ Notification Contacts & - schedules & \\
\hline \multicolumn{5}{|c|}{ NOTIFICATIONS } \\
\hline \multicolumn{5}{|c|}{ Show notifications tagged with } \\
\hline \multicolumn{5}{|c|}{ it +1 to 5 of $5 \rightarrow+1$} \\
\hline \multicolumn{4}{|c|}{ object $\times$} & Active/Paused \\
\hline \multicolumn{4}{|c|}{$\Delta$ Clone of Email to Admin } & Active \\
\hline \multicolumn{4}{|c|}{$\Delta$ Email to Admin } & Active \\
\hline \multicolumn{4}{|c|}{$\triangle$ Email to all members of group PRTG Users Group } & Active \\
\hline \multicolumn{4}{|l|}{$\Delta$ Notification } & Active \\
\hline \multicolumn{4}{|c|}{$\Delta_{\text {Ticket Notification }}$} & Active \\
\hline
\end{tabular}

Gambar 9. Notifikasi Email sudah aktif

\section{HASIL DAN PEMBAHASAN}

Implementasi dilakukan dengan membuat layanan-layanan dimulai dengan penanaman sistem operasi pada server sampai dengan instalasi aplikasi - aplikasi yang diperlukan oleh server. Setelah semua paket telah terpasang, maka hal terpenting yang harus dilakukan adalah melakukan konfigurasi agar semua proses pemantauan jaringan bisa berjalan seperti yang diharapkan.

\section{A. Pengujian PRTG}

Pengujian PRTG diawali dengan melakukan login untuk dapat mengakses menu pada PRTG.Pada saat login pertama kali, telah ditentukan default pemakai adalah "prtgadmin" dengan password adalah "prtgadmin".Pengujian selanjutnya dilakukan dengan pembuatan entri perangkat dan pembuatan grafik dari masing-masing perangkat digunakan untuk menguji aplikasi PRTG.

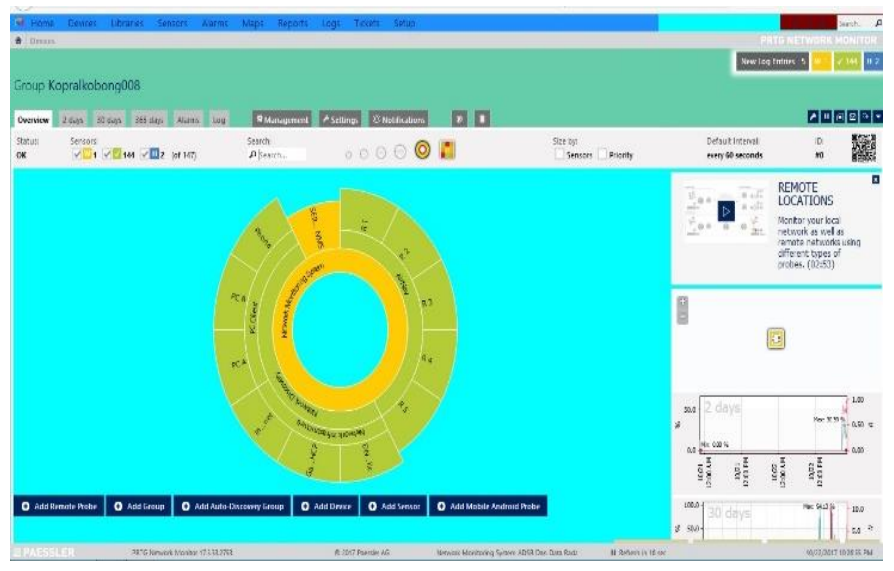

Gambar 10. Tampilan monitoring seluruh perangkat di PRTG

Gambar diatas adalah tampilan secara keseluruhan semua perangkat yang dimonitoring oleh server PRTG dandiimplementsikan pada jaringan Tower ATC Bandara Soekarno-Hatta.Selain itu map PRTG diatas juga digunakan untuk mengingatkan pemakai ketika terjadi masalah pada setiap router yang dimonitor oleh PRTG.

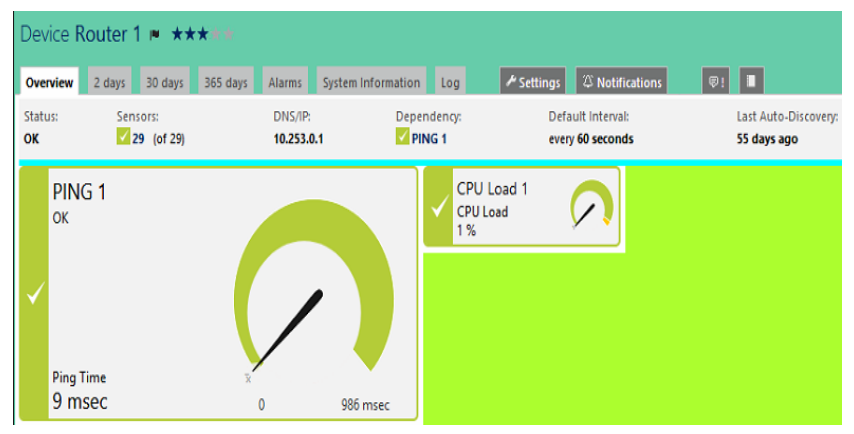

Gambar 11. Kondisi router 1 pada PRTG

Gambar diatas menunjukan bahwa kodisi pada router 1 sangat baik terbukti dengan status ping dan status CPU Load, warna hijau diatas juga membuktikan bahwa perangkat tidak terdapat masalah. 


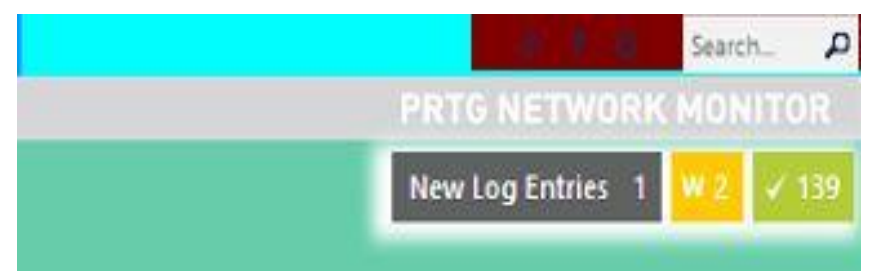

Gambar 12. Notifikasialarm pada PRTG

Gambar diatas terletak pada kanan atas di PRTG, jika terjadi alarm maka aka ada tanda alam berwarna merah beserta jumlah alarm yang terdeteksi oleh PRTG. Pada gambar diatas terdapat log yang mecatat seluruh aktifitas perangkat termasuk sensor yang ada didalamnya, sementara tanda kuning menunjukan warning dan warna hijau menunjukan status perangkat dan sensor yang sedang Up.

Selanjutnya adalah pengujian grafik PRTG terhadap data radar maupun ADSB

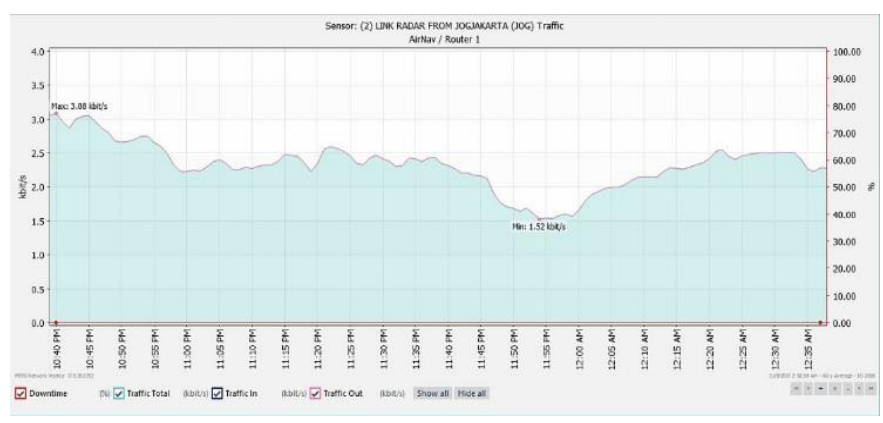

Gambar 13. Grafik data radar Jogja selama 2 jam terakhir

Grafik diatas menunjukan bahwa Outbond/traffic keluar dari radar Jogja pada pukul 22.40 WIB trafik maksimal yang keluarnya adalah 3,85 kilo bytes/second (sekarang), Rata-rata total trafik keluar selama kurun 2 jam ini adalah 21kilo bytes/second, dengan rata-rata kecepatan sebesar 2,82 kilo bytes/second.

\begin{tabular}{|c|c|c|c|c|}
\hline \multirow{2}{*}{ Date Time } & \multicolumn{2}{|c|}{$11 / 8 / 2017$} & \multirow{2}{*}{$\begin{array}{l}\text { Sums (of } \\
2 \text { values) }\end{array}$} & \multirow{2}{*}{$\begin{array}{c}\text { Averages } \\
\text { (of } 2 \text { values) }\end{array}$} \\
\hline & 10:00:00 PM - 11:00:00 PM & 1-12:00:00 AM & & \\
\hline Date Time(RAW) & 43047.66667 & 43047.70833 & & \\
\hline Traffic Total (volume) & 406 KByte & 960 KByte & , 366 KByte & 683 KByte \\
\hline Traffic Total (volume)(RAW) & 416025.0063 & 983242.7675 & & \\
\hline Traffic Total (speed) & $2.72 \mathrm{kbit} / \mathrm{s}$ & $2.19 \mathrm{kbit} / \mathrm{s}$ & & $2.32 \mathrm{kbit} / \mathrm{s}$ \\
\hline Traffic Total (speed)(RAW) & 339.9258 & 273.1435 & & \\
\hline Traffic In (volume) & 0 KByte & 0 KByte & 0 KByte & 0 KByte \\
\hline Traffic In (volume)(RAW) & 0 & 0 & & \\
\hline Traffic In (speed) & $0 \mathrm{kbit} / \mathrm{s}$ & $0 \mathrm{kbit} / \mathrm{s}$ & & $0 \mathrm{kbit} / \mathrm{s}$ \\
\hline Traffic In (speed)(RAW) & 0 & 0 & & \\
\hline Traffic Out (volume) & 406 KByte & 960 KByte & , 366 KByte & 683 KByte \\
\hline Traffic Out (volume)(RAW) & 416025.0063 & 983242.7675 & & \\
\hline Traffic Out (speed) & $2.72 \mathrm{kbit} / \mathrm{s}$ & $2.19 \mathrm{kbit} / \mathrm{s}$ & & $2.32 \mathrm{kbit} / \mathrm{s}$ \\
\hline Traffic Out (speed)(RAW) & 339.9258 & 273.1435 & & \\
\hline Downtime & $0 \%$ & $0 \%$ & & $0 \%$ \\
\hline Downtime(RAW) & 0 & 0 & & \\
\hline Coverage & $34 \%$ & $100 \%$ & & $67 \%$ \\
\hline Coverage(RAW) & 3400 & 9999 & & \\
\hline
\end{tabular}

Gambar 14. Data trafik radar Jogjakarta
Data realtime bisa diunduh dalam format .xml, .csv dan HTMLweb page serta dapat dilihat menggunakan aplikasi Microsoft Excel. File unduhan di atas berisi tentang lalu lintas data radar Jogjakarta dalam jaringan dengan pola pengukuran berulang dan dengan waktu pencuplikan data yang telah diatur sebelumnya.

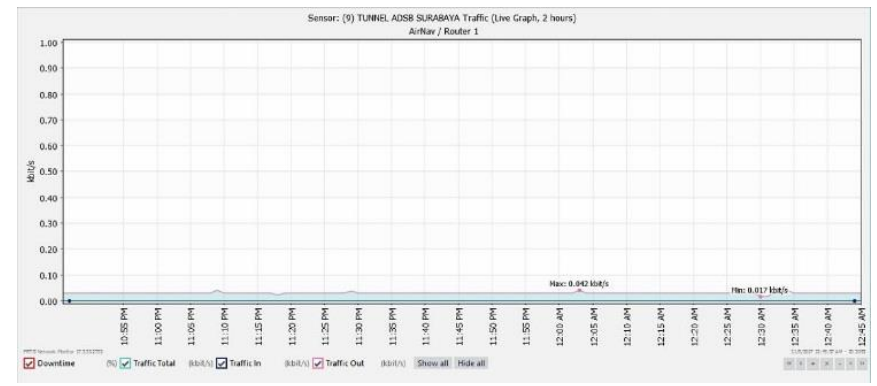

Gambar 15. Grafik ADSB selama 2 jam terakhir

Gambar 15menunjukan bahwa Outbond/traffic keluar dari ADSB Surabaya pada pukul 22.55 WIB traffic maksimal yang keluarnya adalah 0,042 kilo bytes/second (sekarang), Rata-rata total traffic keluar selama kurun 2 jam ini adalah 0,22 kilo bytes/second, dengan rata-rata kecepatan sebesar 0,03 kilo bit/second.

\begin{tabular}{|c|c|c|c|c|}
\hline \multirow{2}{*}{ Date Time } & \multicolumn{2}{|c|}{$11 / 8 / 2017$} & \multirow{2}{*}{$\begin{array}{l}\text { Sums (of } \\
2 \text { values) }\end{array}$} & \multirow{2}{*}{$\begin{array}{c}\text { Averages (of } \\
2 \text { values) }\end{array}$} \\
\hline & 10:00:00 PM - 11:00:00 PM & 11:00:00 PM - 12:00:00 AM & & \\
\hline Date Time(RAW) & $\begin{array}{r}43047.66667 \\
\end{array}$ & \begin{tabular}{|r|}
43047.70833 \\
\end{tabular} & & \\
\hline Traffic Total (volume) & 1.25 KByte & 13763.1847 & 15 KByte & 7.34 KByte \\
\hline Traffic Total & 1.25 KByte & $0.03 \mathrm{kbit} / \mathrm{s}$ & & \\
\hline Traffic Total (speed) & $0.03 \mathrm{kbit} / \mathrm{s}$ & 13 KByte & & $0.03 \mathrm{kbit} / \mathrm{s}$ \\
\hline Traffic Total (speed)(RAW) & 3.8002 & 13763.1847 & & \\
\hline Traffic In (volume) & 0 KByte & $0.03 \mathrm{kbit} / \mathrm{s}$ & 0 KByte & 0 KByte \\
\hline Traffic In (volume)(RAW) & 0 & 3.8234 & & \\
\hline Traffic In (speed) & $0 \mathrm{kbit} / \mathrm{s}$ & 0 KByte & & $0 \mathrm{kbit} / \mathrm{s}$ \\
\hline Traffic In (speed)(RAW) & 0 & 0 & & \\
\hline Traffic Out (volume) & 1.25 KByte & 13 KByte & & \\
\hline Traffic Out (volume)(RAW) & 1276.7012 & 13763.1847 & & \\
\hline Traffic Out (speed) & $0.03 \mathrm{kbit} / \mathrm{s}$ & $0.03 \mathrm{kbit} / \mathrm{s}$ & & \\
\hline Traffic Out (speed)(RAW) & 3.8002 & 3.8234 & & \\
\hline Downtime & $0 \%$ & $0 \%$ & & \\
\hline \begin{tabular}{|l|} 
Downtime(RAW) \\
\end{tabular} & 0 & 0 & & \\
\hline \begin{tabular}{|l|} 
Coverage \\
\end{tabular} & $9 \%$ & $100 \%$ & & $55 \%$ \\
\hline Coverage(RAW) & 933 & 9999 & & \\
\hline
\end{tabular}

Gambar 16. Data trafik ADSB Surabaya

Sama seperti tabel hasil unduhan data radar Jogjakarta, tabel diatas merupakan tabel hasil unduhan dalam bentuk format .csv kemudian dibuka dengan aplikasi Microsoft Excel yang menampilkan lalu lintas data ADSB Surabaya dalam kurun waktu yang sudah ditentukan.

\section{B. Pengujian Email Notifikasi}

Pengujian email notifikasi dimulai dengan melakukan test pengiriman notifikasi ke email administrator, hal ini dilakukan untuk mengechek agar notifikasi yang dikirim sesuia dengan alamat email yang telah ditentukan. Selanjutnya dengan melihat alarm pada PRTG, jika ada alarm secara otomatis PRTG akan mengirimkan email kepada administrator. 


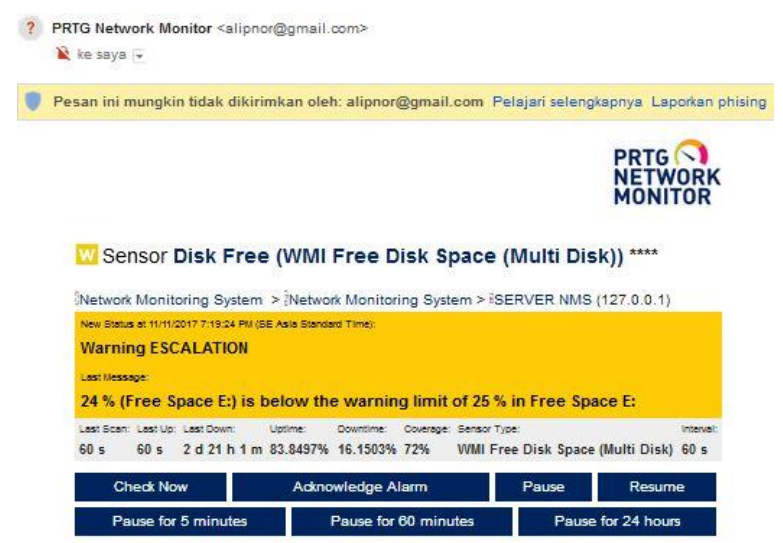

Gambar 17. Notifikasi alarm melalui email berhasil.

Gambar diatas menunjukan bahwa kondisi bahwa drive E pada server hampir penuh karena hanya tersis a $24 \%$ dari total kapasitas yang ada. Pada notifikasi email ini juga menunjukan batas adanya warning adalah $25 \%$.

\section{Pengujian Kecepatan Respon PRTG}

Dari hasil pengujian kecepatan respon PRTG terhadap kondisi perangkat dapat ditarik tabel sebagai berikut:

Tabel 1. Hasil pengujian kecepatan respon PRTG

\begin{tabular}{|l|l|l|l|}
\hline Pengujian Respon & $\begin{array}{l}\text { Waktu Kondisi } \\
\text { perangkat } \\
\text { Down / } \\
\text { Warning }\end{array}$ & $\begin{array}{l}\text { Waktu } \\
\text { kondisi } \\
\text { Down / } \\
\text { Warning } \\
\text { PRTG }\end{array}$ & $\begin{array}{l}\text { Kecepatan } \\
\text { Respon }\end{array}$ \\
\hline Router Down & $18: 19: 10$ & $18: 19: 15$ & 5 detik \\
\hline $\begin{array}{l}\text { Port Down, data } \\
\text { radar/ ADSB } \\
\text { Hilang }\end{array}$ & $18: 25: 00$ & $18: 25: 05$ & 5 detik \\
\hline $\begin{array}{l}\text { Peringatan } \\
\text { kapasitas hardidik }\end{array}$ & $18: 30: 00$ & $18: 30: 04$ & 4 detik \\
\hline
\end{tabular}

Tabel diatas menunjukan bahwa PRTG memiliki respon yang sangat cepat, dimana saat perangkat ataupun port down, dalam waktu 5 detik PRTG akan menunjukan notifikasi alarm. Kemudian jika kapasitas hardisk sudah hampir penuh, maka dalam waktu 4 detik PRTG akan menunjukan notifikasi alarm.

Dari hasil pengujian diatas, maka dapat ditarik table hasil sebagai berikut .

Tabel 2. Perbandingan sebelum dan sesudah menggunakan PRTG Network Monitor

\begin{tabular}{|c|c|c|c|}
\hline No & Parameter & Sebelum Ada PRTG & Sesudah Ada PRTG \\
\hline 1 & $\begin{array}{l}\text { Waktu } \\
\text { Respon } \\
\text { Gangguan }\end{array}$ & $\begin{array}{l}\text { Menunggu laporan } \\
\text { dari ATC } \\
\text { Koordinator } \\
\text { kemudian } \\
\text { melakukan } \\
\text { pengechekan }\end{array}$ & $\begin{array}{l}\text { Engineer Langsung } \\
\text { melakukan } \\
\text { pengechekan ketika } \\
\text { terjadi alarm pada } \\
\text { PTRG }\end{array}$ \\
\hline
\end{tabular}

\begin{tabular}{|c|l|l|l|}
\hline \multirow{3}{*}{2} & History & $\begin{array}{l}\text { Setiap terjadi } \\
\text { gangguan, log } \\
\text { hanya di tulis } \\
\text { manual atau dalam } \\
\text { aplikas excel, } \\
\text { namun terkadang } \\
\text { ada Engineer yang } \\
\text { lupa menulisnya. }\end{array}$ & $\begin{array}{l}\text { Engineer dapat } \\
\text { mempelajari setiap } \\
\text { gangguan y ang ada } \\
\text { bedasarkan tren } \\
\text { yang ada di log } \\
\text { history pada PRTG, } \\
\text { sehingga } \\
\text { penanganan akan } \\
\text { lebih cepat karena } \\
\text { sudah tau cara } \\
\text { mengatasinya. }\end{array}$ \\
\hline 3 & Peforma & $\begin{array}{l}\text { Karena menunggu } \\
\text { info jika terjadi } \\
\text { gangguan, maka } \\
\text { progress pengerjaan } \\
\text { sedikit lebih lama } \\
\text { dan hal tersebut } \\
\text { mengakibatkan } \\
\text { lamanya durasi } \\
\text { gangguan sehingga } \\
\text { mempengaruhi } \\
\text { peforma jaringan. }\end{array}$ & $\begin{array}{l}\text { Peforma jaringan } \\
\text { meningkat, hal itu } \\
\text { dikarenakan jika } \\
\text { terjadi gangguan } \\
\text { akan ada alarm dan } \\
\text { segera diatasi. }\end{array}$ \\
& & \\
\hline
\end{tabular}

\section{KESIMPULAN DAN SARAN}

Interkoneksi yang dilakukan antara kantor cabang dan kantor Tower ATC Bandara Soekarno-Hatta untuk menunjang transportasi penerbangan dengan mengirimkan data radar dan ADSB dapat dikonfigurasikan dengan baik dan dapat diintegrasikan dengan baik menggunakan server PRTG yaitu: semua perangkat router yang menerima aliran dataradar dan ADSB dapat termonitoring dengan memasang SNMP disetiap router. Dengan adanya server PRTG, pengelola dapat langsung melakukan perbaikan jika terdapat alarm tanpa perlu menunggu complain dari pihak pemakai. Dengan adanya server PRTG, pengelola akan menerima notifikai email dengan cepat jika terjadi gangguan pada jaringan yang dimonitor.

\section{DAFTAR PUSTAKA}

[1] K. Shin, N. Shin, S. Choi, and S. Choi, "Systems Engineering Approach to Designing Smart Condition Monitoring Systems for Smart Manufacturing ( ICCAS 2016 )," no. Iccas, 2016.

[2] T. Röhl, J. Eitzinger, G. Hager, and G. Wellein, “2017 IEEE International Conference on Cluster Computing LIKWID Monitoring Stack: A flexible framework enabling job specific performance monitoring for the masses," 2017.

[3] K. V. S. Baba et al., "Synchrophasor Based Real Time Monitoring of Grid Events in Indian Power System," pp. 1-5, 2016.

[4] C. Wei and Z. Yue, "Design and Implementation of Remote Multiple Physiological Parameters Monitoring System," no. 2007.

[5] E. O. Tartan and C. Ciflikli, "An Android Application 
for Geolocation Based Health Monitoring, Consultancy And Alarm System," 2018 IEEE 42nd Annu. Comput.

Softw. Appl. Conf., vol. 01, pp. 341-344, 2018. 
